\title{
Correction to: ZIKV infection effects changes in gene splicing, isoform composition and IncRNA expression in human neural progenitor cells
}

Benxia Hu ${ }^{1,2}$, Yongxia Huo ${ }^{1}$, Liping Yang ${ }^{1}$, Guijun Chen ${ }^{1}$, Minhua Luo ${ }^{3}$, Jinlong Yang ${ }^{4,5}$ and Jumin Zhou ${ }^{1 *}$

Correction to: Virol J (2017) 14:217

https://doi.org/10.1186/s12985-017-0882-6

In the original publication of this article [1], two grants from National Science Foundation of China and Yunnan Provincial Government (U1602226) and National Science Foundation of China(2016YFC1200404) were omitted in the 'Funding' section. The correct 'Funding' section is below.

\section{Funding}

This work was supported by the Ministry of Science and Technology of the People's Republic of China (2016YFA0100900), by a grant from Chinese Academy of Sciences (KSCXZ-EW-BR-6) and a startup fund from Kunming Institute of Zoology, Chinese Academy of Sciences (Y102421081), by grants from Yunnan Provincial Government (2013FA051; 2011HA005) and by National Science Foundation of China (NSFC 81471966, NSFC 81672040 2016YFC1200404) and a joint grant from National Science Foundation of China and Yunnan Provincial Government (U1602226) to JZ.

\section{Author details}

${ }^{1}$ Key Laboratory of Animal Models and Human Disease Mechanisms of the Chinese Academy of Sciences/Key Laboratory of Bioactive Peptides of Yunnan Province, Kunming Institute of Zoology, Kunming 650223, China. ${ }^{2}$ Kunming College of Life Science, University of Chinese Academy of Sciences, Kunming 650204, China. ${ }^{3}$ State Key Laboratory of Virology, CAS Center for Excellence in Brain Science and Intelligence Technology (CEBSIT), Wuhan Institute of Virology, Wuhan 430071, China. ${ }^{4} \mathrm{BGI}-Y u n n a n$, BGI-Shenzhen, Kunming 650000, China. ${ }^{5}$ College of Life Sciences, Yunnan University, Kunming 650091, China.

Received: 18 January 2019 Accepted: 21 January 2019

Published online: 04 February 2019

\section{Reference}

1. Hu, et al. ZIKV infection effects changes in gene splicing, isoform

composition and IncRNA expression in human neural progenitor cells. Virol J. 2017;14:217. https://doi.org/10.1186/s12985-017-0882-6.

\footnotetext{
* Correspondence: zhoujm@mail.kiz.ac.cn

${ }^{1}$ Key Laboratory of Animal Models and Human Disease Mechanisms of the Chinese Academy of Sciences/Key Laboratory of Bioactive Peptides of Yunnan Province, Kunming Institute of Zoology, Kunming 650223, China Full list of author information is available at the end of the article
}

(c) The Author(s). 2019 Open Access This article is distributed under the terms of the Creative Commons Attribution 4.0 International License (http://creativecommons.org/licenses/by/4.0/), which permits unrestricted use, distribution, and reproduction in any medium, provided you give appropriate credit to the original author(s) and the source, provide a link to the Creative Commons license, and indicate if changes were made. The Creative Commons Public Domain Dedication waiver (http://creativecommons.org/publicdomain/zero/1.0/) applies to the data made available in this article, unless otherwise stated. 